as the manufacture of mantles and the raw materials for their production.

The second division of this subject is of no less importance than the first. There are many critical operations in the manufacture of a first-grade mantle. By a critical operation, I mean an operation which if not properly conducted will result in the production of an inferior piece of goods.

It is necessary, therefore, to have not only a carefully organized supervising staff of exceptionally efficient foremen, but also to have a high grade of intelligence in the working force and to teach them to appreciate the importance of the work entrusted to them.

The amount of skill required from the employees and the grade of intelligence demanded will exclude mantle-making from that class of manufacturing industries which use cheap and ignorant help. The proportion of pay-roll which goes to the supervising staff is greater in mantle-making than in any other manufacturing line. The greatest factors contributing to the success of the American mantle manufacturer are:

First.-A thorough study and understanding of the technical difficulties involved in the various different processes.

Second.-A carefully organized and intelligent suvervision of every process.

Third.-The high intelligence, integrity and skill of his employees.

Furthermore, I laid down in the beginning the axiom that any impurity introduced in to the mantle in any of the processes would seriously affect the finished product. This makes it apparent that absolute cleanliness of the entire plant, of every operation and of every operator is imperative. In addition to this, the raw materials in the process must be made under the direct technical supervision and control of the mantle manufacturer.

Discussion by Dr. Charles A. Doremus: Dr. Miner has referred to Drummond as the first one to obtain an incandescent light. He will pardon my reading from a memoir by Prof. Robert Hare. It is entitled "On the Supply and Application of the Blowpipe," published by order of the Philadelphia Chemical Society, I 802 .

Hare made a report to the Society on December Io, I80I, and exhibited experiments with his new apparatus which consisted not only of a blowpipe but also of a hydrostatic reservoir for holding the hydrogen and oxygen in separate compartments to be delivered as required.
On page 29 of this pamphlet the following description of some of his experiments occurs:

"The cock of the pipe communicating with the hydrogen gas was then turned until as much was emitted from the orifice of the cylinder as when lighted formed a flame smaller in size than that of a candle. Under this flame was placed the body to be acted on, supported either by charcoal, or by some more solid, and incombustible substance. The cock retaining the oxygen gas was then turned until the light and heat appeared to have attained the greatest intensity. When this took place, the eyes could scarcely sustain the one, nor could the most refractory substances resist the other." Hare has in many places in his subsequent writings made full claim to the "lime light."

Discussion by Dr. Morris Loeb: In addition to the hypotheses mentioned by the first speaker, it has, at times, been suggested that the oxide of thorium forms a complex with the other oxides, and that luminosity accompanies isomeric changes in this larger nolecule. It has accurred to me that the conversion of heat into luminescence might be well explained on a hypothesis similar to that which was, I believe, first advanced by Huggins, for the explanation of fluorescence by the existence of very large molecular masses. We all know how the presence of phosphoric pentoxide enables tungstic acid to form much larger complexes. Is it not possible that pure thoria does not form large molecules, but that the presence of small quantities of some of the other oxides leads to the formation of the big complex molecule, which transforms the heat waves, rather than transmitting them?

\section{GUAYULE RUBBER. I.}

By Theodore WhitTELSEY.

Received January 22, 1909.

It as long been known that the natives of Mexico in some of their games use balls composed of an elastic substance which they obtain by chewing the bark of a shrub called Guayule:" Attempts have been made from time to time to introduce this substance industrially, but without success until recently. The first practical experimentation on a commercial scale seems to have been made in I903-4. In the following year the product, which has been found to be a true rubber, began to be put on the market. From this time on the industry developed with extraordinary rapidity, and the excitement in northern Mexico is said to have been 
comparable to that in Texas when the oil fields were discovered. By 1906 practically all the Guayule within reach of existing transportation facilities was contracted for.

The Guayule, Parthenium argentatum, is found on the semi-arid lands of the plateau of northern Mexico, growing in the dry, rocky soil of the foothills. It is not large; the dimensions of plants of factory size are approximately as follows:

$\begin{array}{lcc}\text { Height. } & \text { Dry weight. } & \text { Diameter at base of trunk. } \\ 12 \text { inches. } & 6 \text { ounces. } & 7 / 8 \text { inches. } \\ 20 \text { " } & 12 \text { " } & 1 / 1 / 8 " \text { " } \\ 36 \text { " } & 32 ~ & 21 / 4\end{array}$

The average weight of factory shrub is probably between 12 and 16 ounces. The plant shown in the cut is an exceptionally large one, weighing $53 / 4$ lbs. It was $44^{1 / 2}$ inches high and $21 / 4$ inches in diameter at the ground level.

The shrub is collected by pulling up the entire plant, and is pressed either in the field or at the railway station into bales weighing from 80 to 120 kilos. In 1904 these are said to have brought 7 pesos per ton; in 1905 the price had risen to 30 or 40 pesos and recently has been above 100 pesos ( $\mathrm{I}$ peso $=\$ 0.50$ gold) .

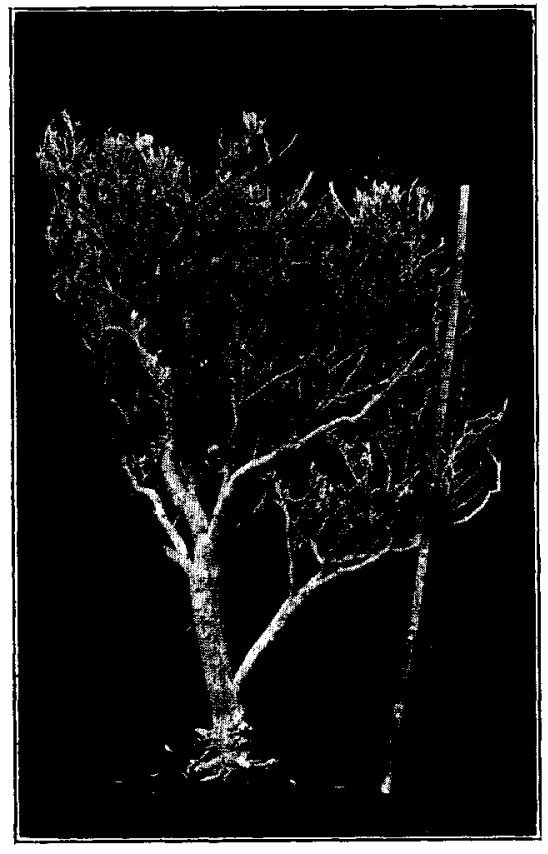

Guayule.1

The Guayule contains in the neighborhood of 9 per cent. of pure rubber, calculated to the perfectly dry plant. The methods that may be used Iloyd. to extract the crude rubber are entirely different from those used with most rubber plants. These contain a milky juice or latex from which the

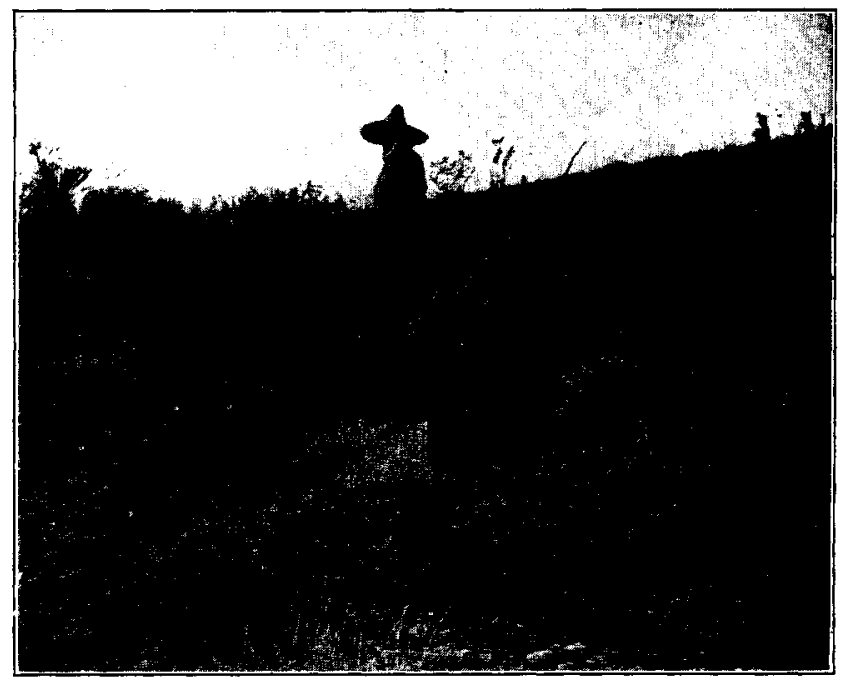

Guayule in the field.

rubber is obtained by coagulation, while in the Guayule the rubber exists as such preformed in the plant. The earlier processes were of three types: (I) the alkali process, in which the shrub was boiled with a solution of caustic alkali; (2) the solution processes in which the rubber was extracted by carbon bisulphide or some other solvent; and (3) the mechanical process. The first of these is still used in apparently only one factory. According to the patent specifications, the ground shrub is boiled with three times its weight of 6 per cent. caustic soda for six hours, after which the rubber is skimmed off and freed from alkali. Of the second class, the carbon bisulphide method has been abandoned, because of the expense and the belief that rubber when recovered from a solvent does not possess certain desirable physical qualities to the same degree as an undissolved rubber. A process that belongs to this type has been extensively experimented with in a new factory during the past two years. This process is said to be based on the extraction of the dried shrub with benzol. A solution of rubber and resin is obtained from which the former is precipitated by the addition of alcohol. It has been prophesied that this process will prove a failure for the same reasons that have led to the abandonment of the bisulphide extraction, but the product is now on the New York market and the outcome is awaited with interest. Rubber produced in this 
way should run lower in resin than that obtained directly by the other processes. The great bulk of the Guayule rubber now coming into the market is obtained by the third, the mechanical process. In this the shrub is crushed and then ground with water in pebble-mills. The rubber in the plant then becomes apparent as small particles $1 / 16$ inch in diameter and from $\mathrm{I} / \mathrm{I} 6$ to $\mathrm{I} / 8$ inch long. The details of the succeeding operations to separate the rubber from the woody matter are for the most part kept secret and doubtless vary in different factories, but it may be said in a general way that the procedure is based on the fact that when soaked with water the woody fiber becomes water-logged and sinks while the rubber being lighter than water floats on the surface of the tanks and is skimmed off. It is then washed, sheeted on steel rolls, and either shipped moist or first dried by hanging the sheets in an airy room or by heating gently in a vacuum. If the mechanical process is properly conducted, a practically complete extraction of the rubber from the shrub is secured.

Guayule rubber obtained by the mechanical process is black on the surface when it reaches the market, but olive to iight brown within. The dry crude rubber contains about 20 per cent. resin. Some factories also produce a brand from which the resin has been in great part extracted, but the demand for this seems comparatively small. Guayule rubber softens more quickly on the rolls than most other rubbers and therefore requires to be handled somewhat differently, but once this is understood, the working of Guayule rubber of good quality presents no difficulty. It can be substituted for many of the African rubbers, is used to advantage in boots and shoes and many other lines of manufacturing, and seems to be growing in favor. The Guayule rubber recently reported as received at the port of New York was, September 850,000 1bs., October 929,500 lbs., November I,444,00o lbs.

NORTHWESTERN UNIVERSITY, EVANSTON, Ill.

GUAYULE RUBBER. II.

\section{DISTRIBUTION OF RUBBER IN DIFFERENT PARTS OF THE SHRUB. \\ BY THEODORE WHITTELSEY. \\ Received January 24, 1909.}

It is generally known to producers of Guayule rubber that more rubber is obtained from the bark. of the shrub than from the wood. Apparently the only published statement on the point is in a paper by Endlich ${ }^{1}$ in which he says that the ratio of the rubber found in the bark to that found in the wood, is approximately 7 to 2 . No analyses are given.

In connection with a study of the chemistry of Guayule, the question of the distribution of rubber in the different parts of the plant has been taken up. The results have turned out to be unexpectedly interesting, and to present problems of technical importance.

The material consisted of air-dried plants of different size, selected so as to represent approximately the ordinary run of factory shrub, viz., Height. Weight. Trunk. Root. Branches and leaves.

1 Large plant. . $3 \mathrm{ft} . \quad 944 \mathrm{~g} . \quad 165 \mathrm{~g} . \quad 125 \mathrm{~g} . \quad 654 \mathrm{~g}$.

2 Medium plants $2 \mathrm{I} / 2 \mathrm{ft} . \quad 747 \mathrm{~g} .165 \mathrm{~g} .132 \mathrm{~g} . \quad \mathbf{4 5 0} \mathrm{g}$.

5 Small plants $2 \mathrm{ft} . \quad 2101 \mathrm{~g} .637 \mathrm{~g} .272 \mathrm{~g} . \quad 1192 \mathrm{~g}$.

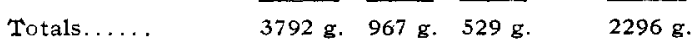

In the division of material the main stem up to the point where its diameter was that of its largest branch was called trunk. The largest branches were less than one-half inch in diameter. The plants had lost most of the leaves in shipment, as is usual, so that the value for "branches and leaves" is practically that of the branches. The trunks and roots were sawed into short pieces (the loss by sawdust amounted to 22 grams in the trunks, 29 grams in the roots) and then steamed until the bark could easily be removed from the wood. A small amount of water-soluble matter was undoubtedly removed in consequence of the steaming, but determinations of water-extractable matter in the whole trunk and in the steamed bark and wood showed that this was negligible. The separate parts were then crushed between steel rolls, dried in vacuum at low temperature, and ground as fine as possible in a coffee mill. The rubber in the bark renders it exceedingly difficult to obtain the material in sufficiently finely divided condition for proper sampling. Many of the particles of bark after the above treatment measured as much as $3 \mathrm{~mm}$. across. This lack of homogeneity manifests itself in the analyses.

\begin{tabular}{|c|c|}
\hline Material. & Dry weight. \\
\hline Trunk bark. & $349 \mathrm{~g}$. \\
\hline Root bark. . . . . . . . . . . & $127 \mathrm{~g}$. \\
\hline Branches and leaves............. & $1918 \mathrm{~g}$. \\
\hline Trunk wood............... & $404 \mathrm{~g}$. \\
\hline Root $\operatorname{wood} \ldots \ldots \ldots \ldots \ldots \ldots \ldots \ldots$ & $255 \mathrm{~g}$. \\
\hline
\end{tabular}

The materials were reduced to convenient quantity by careful quartering. The portion taken for analysis was dried to constant weight in a steam(1905). 